\title{
Editorial
}

\section{The Promise of Integral Education and Integral Drama Based Pedagogy}

As Editors-in-chief for the Beijing international Review of Education we are most grateful to Liwen Ma and Joseph L. Subbiondo who in a genuine collaboration have been working to develop this special issue on Integral Education and the special contribution of drama to it based on East-West perspectives and philosophies of self-cultivation with its theoretical underpinnings in Wang Yangming, Sri Aurobindo, Hiroshi Motoyama, Carl Rogers, Huineng and Ken Wilber. These theoretical approaches all point in the same direction toward holistic education of the whole person with an accent on the integration of physical, cognitive, emotional, moral and spiritual dimensions. In this special issue the reader also has a series of orientations to practice focussed on Integral Drama Based Pedagogy as Ma and Subbiondo express it and relations between drama and child development, language learning and moral development, learning, story-telling and drama, role drama and teaching a famous play. For anyone who has not been introduced to Integral Drama Based Pedagogy and its contribution to Integral Education, then this special issue serves as both a comprehensive guide and a practical orientation. We wish to congratulate the Editors of this special issue and their international contributors from China, US, UK, India, China Taiwan and Norway. Who would contest that drama has the potential to provide a coherent framework for coordinating and harmonizing relevant human practices, methodologies, and experiences of human potential and what the world cultures have to tell us about spiritual, social, and psychological growth.

Integral Drama Based Pedagogy (IDBP) is the name for an educational approach by Liwen Ma, who has been inspired by Wang Yangming (14721529) a Neo-Confucian philosopher who advanced the doctrine of the 'unity 
of knowing and acting' (zhī xíng hé ȳ̄), understood as a refinement of Lu Xiangshan's critique of Zhu Xi and a form of applied ethical self-cultivation: ethical knowing requires something more than mere assent, it requires action as a kind of doing. Taking a leaf from The Great Learning Wang Yangming 'suggests that loving the good is "like loving a lovely sight," while hating evil is "like hating a hateful odor"' (Tiwald and Van Norden 2014, 191; cited by Van Norden, 2019). Wang Yangming's teaching about the unity of knowledge and action was 'a medicine' directed at the 'disease' of dualism. It is a potent criticism of all dualisms and dualistic thinking including that of Descartes in the West that founds modern western epistemology on 'Cogito Ergo Sum' and inaugurates a fundamental split between theory and practice - a problem for epistemology, ethics, psychology and education. Wang's Neo-Confucianism lead him to comment on the steps of ethical self-cultivation in The Great Learning that while there is an ordering of sequence in spiritual training from first to last, 'the training itself is a unified whole'. Wang explains that the great sages all knew of the unity of knowing and acting but sometimes referred to them separately for pedagogical purposes.

As Liwen Ma acknowledges in the essay with Joe Subbiondo ID вP has also been influenced by developments in educational drama: 'This model was initially proposed by Aurobindo Ghosh in the early twentieth century, adapted for US higher education in the mid 2oth Century by Haridas Chaudhuri, and introduced in China by Xu Fancheng in the late twentieth century.' Ghosh's thinking drew on Indian psychology that chimed with Wang's emphasis that avoided the western mind/body problem by regarding both as essentially manifestations of the same creative energy. This thought is the basis for a theory of integral consciousness that includes a spiritual dimension and contemplation as well as exploring inner and outer elements of experience and reflects diverse cultural wisdom traditions. This approach thus also from an educational point of view teaches us to value experiential learning, multiple ways of knowing, transdisciplinary knowledge and holistically views individual learners as part of the collective -culture, history, society, family-to seek unity in diversity. These are the founding principles of Liwen Ma's approach to IDBP that relies on elective affinities between educational drama and drama therapy to highlight and encourage processes of 'self-exploration, self-awareness, selfreflection, and self-integration'.

Liwen Ma also refers to Donald Winnicott (1895-1971), the great English paediatrician and psychoanalyst, who has been very influential in the field of object relations theory and developmental psychology, and for his ideas of the true self (and false self) that is anchored in the sense of being real, fostered by the practices of childhood play that includes the multiple ways in which 
human beings 'play' through art, sport and drama, a form of universal cultural experience derived from play.

As Editors we are very pleased to present Liwen Ma's IDBP, to recognise its innovation, to encourage its practice and its wide engagement with scholars and practitioners from around the world; and to commend Liwen Ma and Joe Subbiondo, and their contributors for providing a lucid, philosophically interesting and practical introduction to IDBP.

\author{
Xudong Zhu \\ Professor; Dean, Faculty of Education, Beijing Normal University, PR China; \\ Editor-in-Chief, Bejing International Review of Education \\ zhuxd@bnu.edu.cn \\ Michael A. Peters \\ Distinguished Professor, Faculty of Education, Beijing Normal University, \\ PR China; Editor-in-Chief, Bejing International Review of Education \\ mpeters@bnu.edu.cn
}

\title{
References
}

Tiwald, Justin and Bryan W. Van Norden (eds.), 2014, Readings in Later Chinese Philosophy: Han to the Twentieth Century, Indianapolis: Hackett Publishing. Van Norden, Bryan, 'Wang Yangming', The Stanford Encyclopedia of Philosophy (Spring 2020 Edition), Edward N. Zalta (ed.), https://plato.stanford.edu/archives/spreo2o/ entries/wang-yangming/. 
